\title{
Morphology of Sterile Anthers and Inheritance of Cytoplasmic-genetic Male Sterility in Zygotic Seedlings of Polyembryonic Acid Citrus
}

\author{
Prita Sari Dewi $^{1, *}$, Akira Wakana ${ }^{2}$, Yuu Tanimoto ${ }^{1}$, Yumiko Fujiwara ${ }^{2}$, Kaori Sakai ${ }^{3}$ \\ and Kohei Kajiwara ${ }^{4}$ \\ ${ }^{1}$ Graduate School of Bioresource and Bioenvironmental Science, Kyushu University, Fukuoka 812-8581, Japan \\ ${ }^{2}$ Faculty of Agriculture, Kyushu University, Fukuoka 812-8581, Japan \\ ${ }^{3}$ Faculty of Agriculture, Kyushu University, Kasuya, Fukuoka 811-2307, Japan \\ ${ }^{4}$ University Farm, Faculty of Agriculture, Kyushu University, Kasuya, Fukuoka 811-2307, Japan
}

In acid citrus, genetic control of male sterility, an important characteristic for breeding seedless fruit cultivars, is not precisely known because of the presence of barriers such as polyembryony and a long juvenile phase. In this study, 22 crosses with 16 male-fertile acid citrus cultivars were carried out and the zygotic seedlings were grafted onto adult satsuma mandarin trees to enhance flowering. Four crosses with two monoembryonic and male-sterile citrus plants (HY16 and 'Kiyomi') were also carried out and zygotic seedlings showing precocious flowering were used to examine the inheritance of male sterility. Of the 26 crosses, 21 with six cultivars as seed parents generated male-sterile and male-fertile zygotic seedlings with various segregation ratios, whereas five crosses with 'Sudachi' as a seed parent generated only male-fertile zygotic seedlings. The sterile anthers were categorized into undeveloped and underdeveloped by their size in most progenies. The result of these crosses showed that eight cultivars with male-sterile cytoplasmic factors of 'Yuzu', lemon, or satsuma mandarin generated male-sterile zygotic seedlings, while 'Sudachi' with male-fertile cytoplasmic factors of pummelo generated only male fertile zygotic seedlings. The result also suggested that a dominant nuclear fertility-restorer gene system comprising one epistatic gene $R_{1}$ and two complementary genes $R_{2}$ and $R_{3}$ controls the restoration of male fertility and male-sterile anther size in acid citrus plants with sterile cytoplasm (S). The complementary gene $R_{3}$ is located downstream from $R_{2}$, and gene $R_{1}$ is epistatic to $R_{2}$ and $R_{3}$ genes. Genotypes $(S) r_{1} r_{1} r_{2} r_{2}$-- are responsible for undeveloped anthers while genotypes $(\mathrm{S}) r_{1} r_{1} R_{2}-r_{3} r_{3}$ are responsible for underdeveloped anthers. The identified genotypes for male sterility in major acid citrus cultivars will contribute to breeding seedless acid cultivars.

Key Words: complementary gene, epistatic gene, fertility-restorer genes $R_{1}, R_{2}$, and $R_{3}$, underdeveloped anther, undeveloped anther.

\section{Introduction}

Seedless fruit is one of the most important objectives of a Citrus breeding program. This may be addressed by using conventional breeding methods, nonconventional breeding approaches and molecular techniques (Raza et al., 2003; Vardi et al., 2008). Conventional methods of breeding seedless Citrus cultivars through hybridization have been exploited successfully using diploid parents with parthenocarpy,

Received; October 1, 2012. Accepted; February 2, 2013.

This study was partially supported by a Grant-in-Aid (KAKENHI No. 18380026) from the Japan Society for the Promotion of Science (JSPS).

* Corresponding author (E-mail: p_saridewi@yahoo.com). male sterility (MS) (Iwamasa, 1966; Sykes and Lewis, 1996), self-incompatibility, and ovule and embryo abortion (Ye et al., 2009; Yoshida et al., 2005). Breeding triploid seedless Citrus cultivars producing highly sterile pollen and embryo sac has also been developed through hybridization of tetraploid and diploid cultivars (Soost and Cameron, 1980, 1985). Non-conventional approaches for seedless citrus breeding include triploid embryo rescue (Aleza et al., 2010), protoplast fusion for producing tetraploid plants as breeding materials $(\mathrm{Wu}$ et al., 2005), cybrid with satsuma mandarin sterile cytoplasm (Cai et al., 2007; Guo et al., 2004) and intergeneric or wide crosses/fusions (Guo et al., 2002; Grosser et al., 1989). Induction of male sterility in Citrus by the chimeric ribonuclease gene has been applied in seeded 'Ponkan' (Li et al., 2002). In these methods, the 
use of male sterile cultivars with parthenocarpic ability is the most commonly applied. In Japan, several seedless cultivars, mainly due to MS, have been produced via conventional methods (Nishiura et al., 1983; Okudai et al., 1991).

MS is defined as a special term for the failure of plants to produce functional anthers, pollen or male gametes (Shivanna and Sawhney, 1997). In Citrus, MS is known in C. aurantifolia (Nakamura, 1943), C. limon hybrids (Frost, 1948), C. medica (Oppenheim and Frankel, 1929), C. sinensis (Nakamura 1943; Osawa, 1912), C. unshiu (Osawa, 1912) and its hybrid cultivars (Iwamasa, 1966), and C.yatsushiro (Nakamura, 1943). According to these reports, microsporogenesis breakdown occurred (1) in a relatively wide range of stages from before meiotic initiation to microspore development or (2) in an early stage of anther development or archesporial cell formation; the former resulted in underdeveloped anthers with imperfect development of microsporangium containing a few dysfunctional or no pollen grains at the end, while the later resulted in undeveloped or aborted anthers along with early degeneration of archesporial cells. Iwamasa (1966) reported that in each of four crosses with satsuma mandarin (C. unshiu) as a seed parent, nearly half of the hybrid progeny was male sterile due to aborted anthers and the other half was male fertile, while a cross of satsuma $\times$ trifoliate orange (Poncirus trifoliata) generated male sterile zygotic seedlings with underdeveloped anthers and male fertile zygotic seedlings with $1: 1$ segregation ratio. Iwamasa (1966) considered that in crosses with satsuma mandarin as a seed parent, MS would be caused by certain combinations of complementary genes or by the interaction between the cytoplasmic factor of the satsuma and certain parental nuclear genes. Yamamoto et al. (1992b, 1997) suggested that a single or two homomeric recessive genes might control aborted anthers appearing among the progenies with satsuma mandarin cytoplasm. When monoembryonic 'Encore' $(C$. nobilis cv. King $\times C$. deliciosa $)$ with typical mandarin cytoplasm, but not with pummelo cytoplasm seen in Kunenbo (C.nobilis) (Yamamoto et al., 1993), were used as a seed parent, zygotic seedlings with aborted anthers were segregated in each of the progenies (Yamamoto et al., 1992a). It has been designated that MS in Citrus is controlled by the interaction between nuclear and cytoplasmic genes (Kaul, 1988) to which satsuma mandarin and 'Encore' are related (Yamamoto et al., 1992a, 1997). Based on the segregation of male sterile seedlings in crosses with 'Kiyomi' tangor $($ C. unshiu $\times$ C. sinensis $)$ as a seed parent, Nakano et al. (2001) proposed a possible genetic controlling system in which three homomeric nuclear genes control undeveloped anther formation. The genes controlling MS in Citrus have not been clarified yet, mainly because of the presence of barriers restricting genetic analysis such as a high degree of nucellar embryony (polyembryony) and very long generation time of five to more than ten years.

Underdeveloped anthers are seen in economically important cultivars of navel orange, satsuma mandarin, and their hybrids. Crosses with satsuma mandarin as a seed parent generated not only male sterile cultivars with undeveloped anthers such as 'Kiyomi' tangor but also those with underdeveloped anthers such as 'Sweet Spring' tangerine-tangelo $(C$. unshiu $\times$ C. hassaku $)$. It seems that genetic analysis of MS has focused on undeveloped anthers but has not taken underdeveloped anthers into account since Iwamasa (1966), probably because of the difficulty of exactly distinguishing underdeveloped from undeveloped anthers. Thus, the parental materials used for genetic analysis are a limited number of cultivars that are monoembryonic and have sterile satsuma cytoplasm.

In this study, 14 polyembryonic Citrus cultivars with male fertile anthers were chosen as seed and pollen parents to increase cross combinations and to increase the ability to elucidate the complexity of MS-controlling genes. Monoembryonic cultivar 'Kiyomi' with undeveloped anthers and monoembryonic hybrid seedling HY16 $($ C. hanaju $\times$ C. junos $)$ with underdeveloped anthers were used as seed parents to determine the MS genotypes of acid citrus cultivars.

\section{Materials and Methods}

\section{Plant materials}

The extent of polyembryony, male fertility and the scientific names of 17 Citrus cultivars and one hybrid seedling used in this study are listed in Table 1. Of the seventeen cultivars, eight with one of four different kinds of cytoplasm were chosen as seed parents for cross experiments. These cultivars were grown in Sasaguri Orchard of Kyushu University Farm, Fukuoka, Japan.

\section{Discrimination of zygotic from nucellar seedlings}

In 22 cross combinations with the 13 male fertile Citrus cultivars, pollination was performed in May 1991 and 1992. Flower buds one day before anthesis were emasculated, hand-pollinated with the pollen of the target cultivar, and bagged to prevent pollination with alien pollen. Seeds were collected from mature fruit in autumn of that year; the lower the extent of polyembryony in the pistillate parent, the higher the number of monoembryonic seeds containing only zygotic embryo produced. The rate of monoembryonic seeds ranged from about $80 \%$ of seeds for crosses with 'Lisbon' lemon and 'Hanayu' as seed parents to about $1 \%$ of seeds for cross with 'Kabusu' sour orange as a seed parent. Zygotic seedlings were obtained by sowing only monoembryonic seeds in the autumn of each year, and allowed to grow for about one year in a greenhouse. Seedling morphology, such as leaf shape and thorniness, was carefully compared with nucellar seedlings obtained from polyembryonic seeds. Only those suspected to be 
Table 1. Characteristics of Citrus plants used in this study.

\begin{tabular}{|c|c|c|c|}
\hline Cultivar and hybrid & Scientific name & $\begin{array}{c}\text { Polyembryony } \\
\text { (Mean no. of embryos per seed) }{ }^{z}\end{array}$ & Male fertility ${ }^{y}$ \\
\hline Etrog citron & C. medica L. var. ethrog Engl. & monoembryonic (1.0) & MF \\
\hline Eureka lemon & C. limon (L.) Burm.f. & polyembryonic (3.5) & MF \\
\hline Lisbon lemon & C. limon (L.) Burm.f. & polyembryonic (1.4) & MF \\
\hline Kusaie lime & C. limonia Osbech & polyembryonic (1.7) & MF \\
\hline Foster Pink grapefruit & C. paradisi Macfad. & polyembryonic (ne) & $\mathrm{MF}$ \\
\hline Marsh grapefruit & C. paradisi Macfad. & Polyembryonic (ne) & MF \\
\hline Kabusu & C. aurantium $\mathrm{L}$. & polyembryonic (7.8) & MF \\
\hline Bouquet des Fleurs & C. aurantium L. var. crispa Y. Tanaka & polyembryonic (2.7) & MF \\
\hline Chinotto & C. myrtifolia Raf. & polyembryonic (5.0) & MF \\
\hline Yuzu & C. junos Sieblod ex Tanaka & polyembryonic (2.4) & MF \\
\hline Hanayu & C. hanaju Sieblod ex Shirai & polyembryonic (1.1) & MF \\
\hline HY16 & C. hanaju $\times$ C. junos & monoembryonic (1.0) & MS \\
\hline Sudachi & C. sudachi hort. ex Tanaka & polyembryonic (4.1) & MF \\
\hline Yuko & C. yuko hort. ex Tanaka & polyembryonic (ne) & MF \\
\hline Kabosu & C. sphaerocarpa hort. ex Tanaka & polyembryonic (17.5) & MF \\
\hline Kizu & C. kizu hort. ex Y. Tanaka & polyembryonic (15.8) & MF \\
\hline Kiyomi & C. unshiu $\times$ C. sinensis & monoembryonic (1.0) & MS \\
\hline
\end{tabular}

${ }^{z}$ No. of embryos per seed was counted under a stereoscopic microscope and averaged for twenty seeds examined in each cultivar; ne: not examined.

y MF: male fertile; MS: male sterile.

nucellar were analyzed for hybridity with three glutamate oxaloacetate transaminase isozyme genes, Got-1, Got2 , and Got-3, according to the procedure described by Rahman et al. (2001) and Ngo et al. (2011). Zygotic seedlings with the hybrid characteristics were grafted onto 20-year-old 'Miyagawa-wase' satsuma mandarin trees to enhance the growth of the seedlings.

\section{Application of precocious flowering to rapid genetic analysis}

Precocious flowering, or temporary flowering in several-month-old seedlings once during a long juvenile period, is known in Citrus (Furr et al., 1947; Iwamasa and Oba, 1973; Kim et al., 2010), and is a powerful tool for rapid genetic analysis of MS in Citrus cultivars with a very long juvenile phase of their progeny. Male sterile 'Kiyomi' with aborted anthers is monoembryonic and has the ability to generate zygotic seedlings exhibiting precocious flowering (Yamada et al., 1991). Male-sterile HY16 (C. hanaju $\times$ C.junos) with underdeveloped anthers is also monoembryonic and has the ability to generate zygotic seedlings showing precocious flowering with high frequency (Wakana et al., 2005). In this study, 'Kiyomi' and HY16 exhibiting different phenotypes for MS were pollinated with 'Yuzu', 'Foster Pink' grapefruit and 'Marsh Seedless' grapefruit in 2008-2010 to determine the MS genotypes of male-fertile acid citrus cultivars. 'Yuzu', 'Foster Pink' grapefruit, and 'Marsh Seedless' grapefruit also have the ability to generate zygotic seedlings exhibiting precocious flowering (Kim et al., 2010; Yamada et al., 1991). Zygotic seedlings that showed precocious flowering or those that did not show flowering in the first year of seed sowing were decapitated in autumn and allowed to grow new axial shoots during autumn outdoors to induce precocious flowering of the new shoots in spring (Kim et al., 2010). Decapitation treatment was also carried out in the third year after sowing to induce precocious flowering again on the newly developed shoots of the decapitated seedlings. Thus, sterile anthers were observed three times with multiple flowers per seedling after seed sowing. Male-sterile flowers of all hybrids showed consistent MS in the second and third years after seed sowing.

\section{Male fertility (MF) and MS determination}

More than ten years after grafting onto satsuma mandarin trees, MS in each zygotic seedling was visually determined with anthers collected from about 50 balloonshaped flower buds just before anthesis. Zygotic seedlings that produced normal large yellow anthers dehiscing to release yellow pollen were determined to be male fertile, whereas those that had very small to medium-sized pale-cream or white anthers without pollen were determined to be male sterile. These observations were carried out at the full bloom stage in a year of fruit production and replicated for more than three years in each of the zygotic seedlings.

\section{Microscopic observations of anther morphology}

Ten typical flower buds with new leaves were collected one day before anthesis from each of the malefertile and male-sterile zygotic seedlings derived from six crosses with 'Hanayu', 'Lisbon', 'Yuzu', 'Kabosu', and 'Yuko'. The length of the ten flower buds was measured with vernier calipers and averaged for each zygotic seedling, and the mean length of flower buds of 
fertile and sterile seedlings was calculated for each progeny. Three typical stamens were extracted from five of the ten flower buds, and then the length of filaments and length and width of anthers were measured under a stereoscopic microscope equipped with a micrometer. The size of anthers in each zygotic seedling was revealed as volume (mean width $\times$ mean width $\times$ mean length), and averaged for fertile and sterile seedlings in each progeny.

For the observation of microsporogenesis, anthers were extracted from flower buds $2 \mathrm{~mm}, 5 \mathrm{~mm}$, and $8 \mathrm{~mm}$ long in male-sterile and male-fertile zygotic seedlings from several crosses described above. The anthers were fixed with FAA (formalin : acetic acid: $50 \%$ ethanol $=5$ : $5: 90 \mathrm{v} / \mathrm{v}$ ) and stored at $4^{\circ} \mathrm{C}$ until used. Fixed materials were dehydrated in an ethanol-n-butanol series and embedded in paraffin. Anthers were sectioned at $12 \mu \mathrm{m}$ and stained with $0.25 \%$ Heidenhein's hematoxylin. The stained anther sections were observed using a Nikon E800 microscope.

\section{Statistical analysis}

The chi-square test was applied to test the goodness of fit of the expected ratios for the segregation of seedlings with male fertility and MS in all the progenies. Significant differences between male-fertile and malesterile stamens were tested by $t$-test. The chi-square test was also applied to test the goodness of fit of the expected ratios for the segregation of seedlings with undeveloped and underdeveloped anthers in some of the progenies.

\section{Results}

In 22 cross combinations (described as 22 families from F1 to F26 in Table 2) with 14 acid citrus cultivars,

Table 2. Segregation of male-sterile (MS) and male-fertile (MF) seedlings derived from 26 crosses with 16 Citrus cultivars and one zygotic seedling.

\begin{tabular}{|c|c|c|c|c|c|c|c|c|}
\hline \multirow{2}{*}{ Family } & \multirow{2}{*}{ Cross } & \multirow{2}{*}{$\begin{array}{l}\text { Estimated genotypes for three } \\
\text { nuclear fertility-restorer genes }\end{array}$} & \multicolumn{2}{|c|}{ Observed ratio } & \multirow{2}{*}{$\begin{array}{c}\text { Expected ratio } \\
\text { MF : MS }(L: S)^{v}\end{array}$} & \multirow{2}{*}{$\chi^{2}$} & \multirow{2}{*}{$P$} & \multirow{2}{*}{ 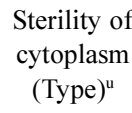 } \\
\hline & & & MF & MS & & & & \\
\hline F1 & Eureka $\times$ Yuzu & $R_{1} r_{1} R_{2} r_{2} r_{3} r_{3} \times R_{1} r_{1} r_{2} r_{2} R_{3} r_{3}$ & 12 & 1 & $13: 3(1: 2)$ & 1.0434 & 0.307 & S (L) \\
\hline $\mathrm{F} 2$ & Lisbon $\times$ Chinotto & $R_{1} r_{1} R_{2} r_{2} r_{3} r_{3} \times R_{1} r_{1} R_{2} r_{2} R_{3} R_{3}$ & 7 & 0 & $15: 1(0: 1)$ & 0.4667 & 0.495 & $\mathrm{~S}(\mathrm{~L})$ \\
\hline F3 & Lisbon $\times$ Yuzu & $R_{1} r_{1} R_{2} r_{2} r_{3} r_{3} \times R_{1} r_{1} r_{2} r_{2} R_{3} r_{3}$ & 26 & 2 & $13: 3(1: 2)$ & 2.4763 & 0.116 & $\mathrm{~S}(\mathrm{~L})$ \\
\hline $\mathrm{F} 4$ & Lisbon $\times$ Yuko & $R_{1} r_{1} R_{2} r_{2} r_{3} r_{3} \times r_{1} r_{1} R_{2} r_{2} R_{3} r_{3}$ & 20 & 11 & $11: 5(3: 2)$ & 0.2587 & 0.611 & $\mathrm{~S}(\mathrm{~L})$ \\
\hline F5 & Lisbon $\times$ Kabosu & $R_{1} r_{1} R_{2} r_{2} r_{3} r_{3} \times r_{1} r_{1} R_{2} r_{2} R_{3} r_{3}$ & 21 & 11 & $11: 5(3: 2)$ & 0.1455 & 0.703 & $\mathrm{~S}(\mathrm{~L})$ \\
\hline F6 & Lisbon $\times$ Kizu & $R_{1} r_{1} R_{2} r_{2} r_{3} r_{3} \times r_{1} r_{1} R_{2} r_{2} R_{3} r_{3}$ & 6 & 4 & $11: 5(3: 2)$ & 0.3564 & 0.551 & $\mathrm{~S}(\mathrm{~L})$ \\
\hline F7 & Kabusu $\times$ Lisbon & $R_{1} r_{1} R_{2} r_{2} R_{3} R_{3} \times R_{1} r_{1} R_{2} r_{2} r_{3} r_{3}$ & 13 & 0 & $15: 1(0: 1)$ & 0.8667 & 0.352 & S?(L?) \\
\hline F8 & Hanayu $\times$ Lisbon & $r_{1} r_{1} R_{2} r_{2} R_{3} r_{3} \times R_{1} r_{1} R_{2} r_{2} r_{3} r_{3}$ & 46 & 18 & $11: 5(3: 2)$ & 0.1636 & 0.686 & $\mathrm{~S}(\mathrm{Y})$ \\
\hline F9 & Hanayu $\times$ Bouquet & $r_{1} r_{1} R_{2} r_{2} R_{3} r_{3} \times$ one of 9 genotypes $^{y}$ & 1 & 1 & - & - & - & $\mathrm{S}(\mathrm{Y})$ \\
\hline F10 & Hanayu $\times$ Chinotto & $r_{1} r_{1} R_{2} r_{2} R_{3} r_{3} \times R_{1} r_{1} R_{2} r_{2} R_{3} R_{3}$ & 15 & 2 & $7: 1(0: 1)$ & 0.0084 & 0.927 & $\mathrm{~S}(\mathrm{Y})$ \\
\hline F11 & Hanayu $\times$ Yuzu & $r_{1} r_{1} R_{2} r_{2} R_{3} r_{3} \times R_{1} r_{1} r_{2} r_{2} R_{3} r_{3}$ & 37 & 11 & $11: 5(1: 4)$ & 1.5515 & 0.213 & $\mathrm{~S}(\mathrm{Y})$ \\
\hline F12 & Hanayu $\times$ Sudachi & $r_{1} r_{1} R_{2} r_{2} R_{3} r_{3} \times R_{1} r_{1} R_{2} r_{2} r_{3} r_{3}$ & 12 & 3 & $11: 5(3: 2)$ & 0.8836 & 0.347 & $\mathrm{~S}(\mathrm{Y})$ \\
\hline F13 & Hanayu $\times$ Kabosu & $r_{1} r_{1} R_{2} r_{2} R_{3} r_{3} \times r_{1} r_{1} R_{2} r_{2} R_{3} r_{3}$ & 31 & 19 & $9: 7(3: 4)$ & 0.6717 & 0.412 & $\mathrm{~S}(\mathrm{Y})$ \\
\hline F14 & Yuzu $\times$ Etrog & $R_{1} r_{1} r_{2} r_{2} R_{3} r_{3} \times$ one of 11 genotypes $^{\mathrm{x}}$ & 5 & 2 & - & - & - & $\mathrm{S}(\mathrm{Y})$ \\
\hline F15 & Yuzu $\times$ Lisbon & $R_{1} r_{1} r_{2} r_{2} R_{3} r_{3} \times R_{1} r_{1} R_{2} r_{2} r_{3} r_{3}$ & 1 & 1 & $13: 3(1: 2)$ & 1.2821 & 0.258 & $\mathrm{~S}(\mathrm{Y})$ \\
\hline F16 & Yuzu $\times$ Kusaie & $R_{1} r_{1} r_{2} r_{2} R_{3} r_{3} \times r_{1} r_{1} R_{2} r_{2} R_{3} r_{3}$ & 26 & 15 & $11: 5(1: 4)$ & 0.5432 & 0.461 & $\mathrm{~S}(\mathrm{Y})$ \\
\hline F17 & Yuzu $\times$ Kabusu & $R_{1} r_{1} r_{2} r_{2} R_{3} r_{3} \times R_{1} r_{1} R_{2} r_{2} R_{3} R_{3}$ & 37 & 2 & $7: 1(0: 1)$ & 1.9377 & 0.164 & $\mathrm{~S}(\mathrm{Y})$ \\
\hline F18 & Yuzu $\times$ Kabosu & $R_{1} r_{1} r_{2} r_{2} R_{3} r_{3} \times r_{1} r_{1} R_{2} r_{2} R_{3} r_{3}$ & 15 & 6 & $11: 5(1: 4)$ & 0.0701 & 0.791 & $\mathrm{~S}(\mathrm{Y})$ \\
\hline F19 & Yuzu $\times$ Kizu & $R_{1} r_{1} r_{2} r_{2} R_{3} r_{3} \times r_{1} r_{1} R_{2} r_{2} R_{3} r_{3}$ & 6 & 4 & $11: 5(1: 4)$ & 0.3564 & 0.551 & $\mathrm{~S}(\mathrm{Y})$ \\
\hline F20 & HY $16 \times$ Foster Pink & $r_{1} r_{1} R_{2} r_{2} r_{3} r_{3} \times$ one of 2 genotypes $^{\mathrm{w}}$ & 80 & 78 & $1: 1(1: 0)$ & 0.0253 & 0.874 & $\mathrm{~S}(\mathrm{Y})$ \\
\hline F21 & HY16 × Marsh & $r_{1} r_{1} R_{2} r_{2} r_{3} r_{3} \times$ one of 2 genotypes $^{\mathrm{w}}$ & 11 & 7 & $1: 1(1: 0)$ & 0.8889 & 0.346 & $\mathrm{~S}(\mathrm{Y})$ \\
\hline $\mathrm{F} 22$ & HY16 × Yuzu & $r_{1} r_{1} R_{2} r_{2} r_{3} r_{3} \times R_{1} r_{1} r_{2} r_{2} R_{3} r_{3}$ & 38 & 22 & $5: 3(1: 2)$ & 0.0178 & 0.894 & $\mathrm{~S}(\mathrm{Y})$ \\
\hline F23 & Sudachi $\times$ Kabosu & $R_{1} r_{1} R_{2} r_{2} r_{3} r_{3} \times r_{1} r_{1} R_{2} r_{2} R_{3} r_{3}$ & 18 & 0 & $11: 5(3: 2)$ & 8.1818 & 0.004 & $\mathrm{~N}(\mathrm{P})$ \\
\hline F24 & Sudachi $\times$ Lisbon & $R_{1} r_{1} R_{2} r_{2} r_{3} r_{3} \times R_{1} r_{1} R_{2} r_{2} r_{3} r_{3}$ & 7 & 0 & $3: 1(3: 1)$ & 2.3333 & 0.127 & $\mathrm{~N}(\mathrm{P})$ \\
\hline $\mathrm{F} 25$ & Sudachi $\times$ Yuzu & $R_{1} r_{1} R_{2} r_{2} r_{3} r_{3} \times R_{1} r_{1} r_{2} r_{2} R_{3} r_{3}$ & 21 & 0 & $13: 3(1: 2)$ & 3.8889 & 0.049 & $\mathrm{~N}(\mathrm{P})$ \\
\hline F26 & Kiyomi $\times$ Foster Pink & $r_{1} r_{1} r_{2} r_{2} R_{3} r_{3} \times$ one of 2 genotypes ${ }^{\mathrm{w}}$ & 129 & 38 & $3: 1(1: 0)$ & 0.4491 & 0.503 & $\mathrm{~S}(\mathrm{M})$ \\
\hline
\end{tabular}

${ }^{z}$ Genes $R_{1}, R_{2}$, and $R_{3}$ are dominant to genes $r_{1}, r_{2}$, and $r_{3}$, respectively, and gene $r_{1}$ is epistatic to $r_{2}$ and $r_{3}$. The gene $r_{2}$ and $r_{3}$ are complementary (see Fig. 9).

y $R_{1} R_{1} R_{2} r_{2} R_{3} r_{3}, r_{1} r_{1} R_{2} r_{2} R_{3} R_{3}, R_{1} r_{1} R_{2} r_{2} R_{3} R_{3}, R_{1} r_{1} R_{2} r_{2} R_{3} r_{3}, R_{1} r_{1} R_{2} r_{2} R_{3} r_{3}, r_{1} r_{1} R_{2} r_{2} R_{3} r_{3}, R_{1} r_{1} r_{2} r_{2} R_{3} r_{3}, R_{1} r_{1} R_{2} r_{2} r_{3} r_{3}$, or $R_{1} r_{1} r_{2} r_{2} r_{3} r_{3}$.

${ }^{\times} R_{1} r_{1} R_{2} r_{2} R_{3} R_{3}, r_{1} r_{1} R_{2} r_{2} R_{3} R_{3}, R_{1} r_{1} R_{2} r_{2} R_{3} R_{3}, R_{1} r_{1} R_{2} R_{2} R_{3} r_{3}, r_{1} r_{1} R_{2} R_{2} R_{3} r_{3}, R_{1} r_{1} R_{2} r_{2} R_{3} r_{3}, r_{1} r_{1} R_{2} r_{2} R_{3} r_{3}, R_{1} r_{1} r_{2} r_{2} R_{3} r_{3}, R_{1} r_{1} R_{2} R_{2} r_{3} r_{3}, R_{1} r_{1} R_{2} r_{2} r_{3} r_{3}$, or $R_{1} r_{1} r_{2} r_{2} r_{3} r_{3}$.

${ }^{\mathrm{w}} r_{1} r_{1} R_{2} R_{2} R_{3} r_{3}$, or $R_{1} r_{1} R_{2} R_{2} r_{3} r_{3}$.

${ }^{v} \mathrm{~L}$ : $\mathrm{S}$ in parentheses indicates the expected segregation ratio of male-sterile zygotic seedlings with large or underdeveloped anthers (L) and those with small or undeveloped anthers (S).

"S: sterile cytoplasm; N: normal fertile cytoplasm. Letters in parentheses show cytoplasm (mitochondria) type, i.e., (M) mandarin cytoplasm, (P) pummelo cytoplasm, (Y) yuzu cytoplasm, (L) lemon cytoplasm (Abkenar et al., 2008; Yamamoto et al., 1993). 


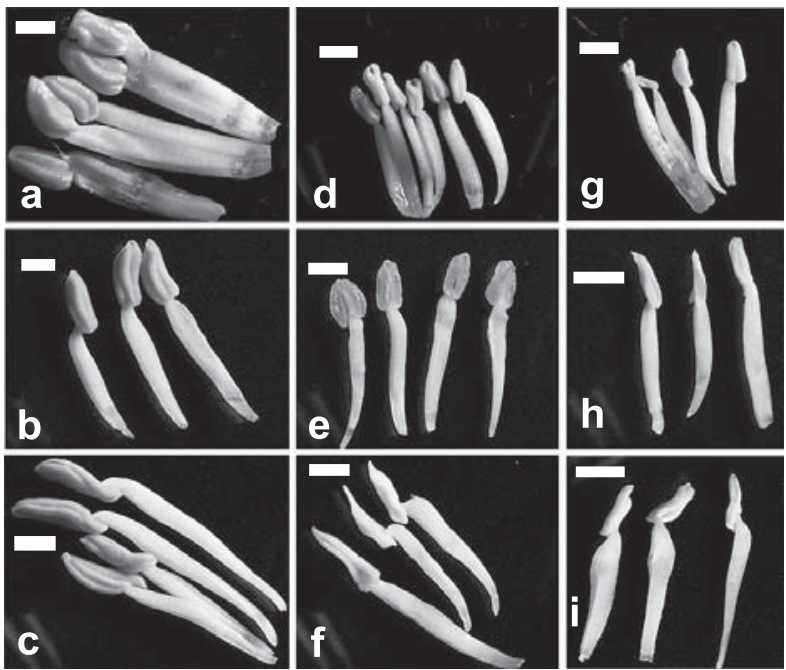

Fig. 1. Comparison of fertile stamens (left) and sterile stamens (center and right) extracted from balloon flower buds of nine zygotic seedlings from the crosses of 'Yuzu' $\times$ 'Kabosu' (F17; a, d, g), 'Yuzu' $\times$ 'Kusaie Lime' (F16; b, e, h), and 'Lisbon' ×'Yuko' (F4; c, f, i). Undeveloped anthers were seen in $\mathrm{d}, \mathrm{g}, \mathrm{h}$, and $\mathrm{i}$, while underdeveloped anthers were seen in e and f. Very thin filaments were seen in d. Bars $=2 \mathrm{~mm}$.

498 adult zygotic seedlings grafted onto satsuma mandarin trees were available for genetic analysis of MS, which was found in 110 zygotic seedlings derived from 17 of the 22 cross combinations (Table 2, Fig. 1). The rate of male-sterile seedlings varied from $50 \%$ $(1 / 2)$ for $\mathrm{F} 9$ to $5.2 \%(2 / 39)$ for F17.

When crosses were carried out with 'Lisbon' lemon as a seed or pollen parent (Figs. 1 and 4), the rate of male-sterile seedlings obtained was $7.1 \%(2 / 28)$ for F3, $35.5 \%(11 / 31)$ for $\mathrm{F} 4,34.4 \%(11 / 32)$ for $\mathrm{F} 5,40 \%(4 / 10)$ for F6, 28.1\% (18/64) for F8, 0\% for F2, F7, and F24. The rate of sterile seedlings from a cross of 'Eureka' $\times$ 'Yuzu' (F1) was similar to that from a 'Lisbon' $\times$ 'Yuzu' cross (F3), i.e., 7.7\% (1/13) and 7.1\% (2/28) respectively. When 'Kabusu' sour orange was used as a seed parent, no male-sterile seedling appeared among 13 zygotic seedlings (F7).

When 'Hanayu' was used as a seed parent (Figs. 2, 3 , and 4 ), the rate of male-sterile seedlings was $28.1 \%$ $(18 / 64)$ for $\mathrm{F} 8,50 \%(1 / 2)$ for $\mathrm{F} 9,11.8 \%(2 / 17)$ for $\mathrm{F} 10$, $22.9 \%(11 / 48)$ for $\mathrm{F} 11,20 \%(3 / 15)$ for $\mathrm{F} 12$, and $38 \%$ $(19 / 50)$ for F13. When 'Yuzu' was used as a seed parent, the rate of male-sterile seedlings was $28.6 \%(2 / 7)$ for $\mathrm{F} 14,50 \%(1 / 2)$ for $\mathrm{F} 15,36.6 \%(15 / 41)$ for $\mathrm{F} 16,5.1 \%$ $(2 / 39)$ for $\mathrm{F} 17,28.6 \%(6 / 21)$ for $\mathrm{F} 18$, and $40 \%(4 / 10)$ for F19.

When 'Sudachi' was used as a seed parent, no malesterile seedling was found among 46 zygotic seedlings (F23, F24, and F25).

The morphology of flowers in male-sterile zygotic seedlings was compared with that in male-fertile zygotic seedlings in six families F4, F5, F8, F11, F13, and F18 (Table 3, Figs. 1, 2, 3, and 4). The flower bud length,
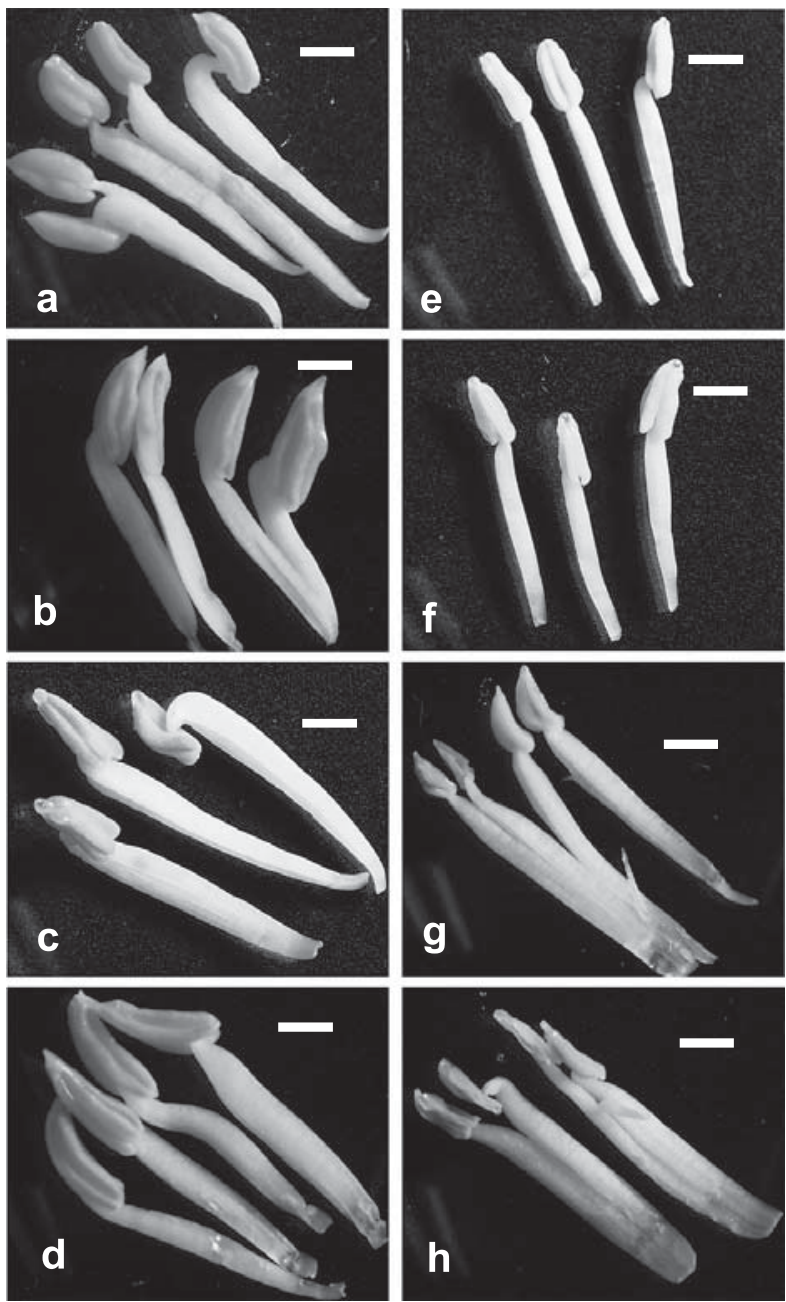

Fig. 2. Fertile (a, b, c, d) and sterile stamens (e, f, g, h) extracted from balloon flower buds of four male-fertile and four malesterile zygotic seedlings derived from a cross of 'Hanayu' $\times$ 'Kabosu' (F13), respectively. The right photos show that anthers were undeveloped and very small, and their filaments were thin. Bars $=2 \mathrm{~mm}$.

anther length, and anther width in male-sterile seedlings were significantly smaller than those of male-fertile seedlings. Filament length was not significantly different between male-fertile and male-sterile seedlings, except for F4 and F18 progenies wherein filaments in malesterile seedlings were significantly shorter than those in male-fertile seedlings. The mean volume of anthers in male-sterile seedlings was significantly smaller than that in male-fertile seedlings in each progeny.

Frequency distribution of male-sterile seedlings with different anther volume showed that they were roughly divided into two groups, i.e., those with large and small sterile anthers (Fig. 5). In male-sterile seedlings from a 'Hanayu' $\times$ 'Yuzu' cross (F11), the volumes of small sterile anthers ranged between $1 \mathrm{~mm}^{3}$ and $2.5 \mathrm{~mm}^{3}$, while those of large sterile anthers ranged between $4.5 \mathrm{~mm}^{3}$ and $5.5 \mathrm{~mm}^{3}$. In male-sterile seedlings from a 'Hanayu' $\times$ 'Kabosu' cross (F13), the volumes of small sterile anthers ranged from $0.3 \mathrm{~mm}^{3}$ and $2.0 \mathrm{~mm}^{3}$, while those 

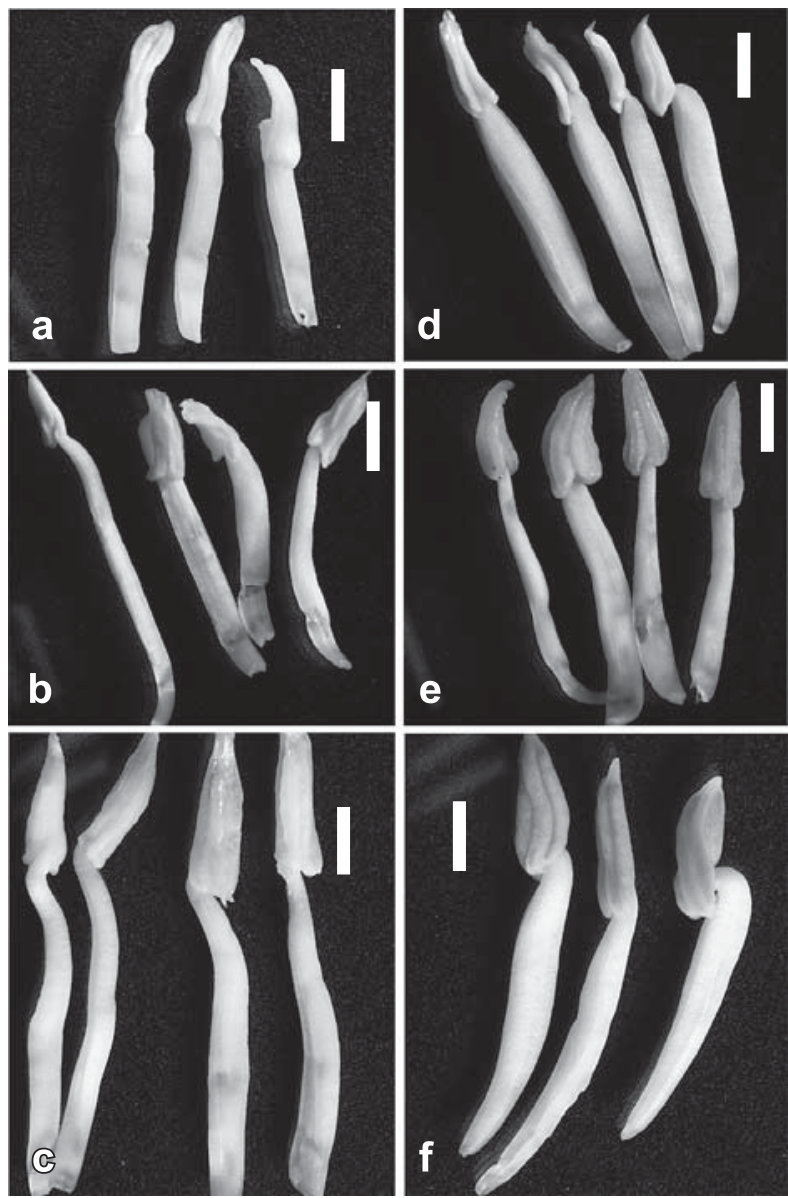

Fig. 3. Stamens extracted from balloon flower buds of five malesterile and one male-fertile zygotic seedlings derived from a cross of 'Hanayu' $\times$ 'Lisbon' (F8). a, b, and d: undeveloped white anthers, e: underdeveloped anthers, c: underdeveloped large anthers containing a small amount of degenerated microspores, f: fertile stamens with normal yellow anthers containing a large amount of pollen. Bars $=2 \mathrm{~mm}$.
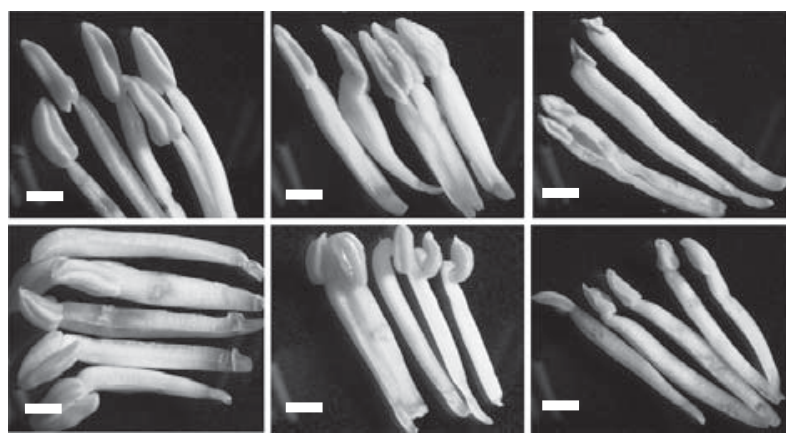

Fig. 4. Fertile yellow anthers (left), sterile underdeveloped anthers (middle) and sterile undeveloped anthers (right) extracted from balloon flower buds of two male-fertile and four male-sterile zygotic seedlings derived from the crosses of 'Lisbon' $\times$ 'Kabosu' (F5; upper) and 'Hanayu' $\times$ 'Yuzu' (F11; lower). Bars $=2 \mathrm{~mm}$.

of large sterile anthers ranged between $2.0 \mathrm{~mm}^{3}$ and $4.0 \mathrm{~mm}^{3}$. In male-sterile seedlings from a 'Hanayu' $\times$ 'Lisbon' cross (F8), the volumes of small sterile anthers ranged between $1.0 \mathrm{~mm}^{3}$ and $3.5 \mathrm{~mm}^{3}$, while those of large sterile anthers ranged between $4.5 \mathrm{~mm}^{3}$ and $8.5 \mathrm{~mm}^{3}$. In six male-sterile seedlings from a 'Yuzu' $\times$ 'Kabosu' cross (F18), the volume of small sterile anthers ranged between $0.2 \mathrm{~mm}^{3}$ and $2.5 \mathrm{~mm}^{3}$, while large sterile anthers were not seen (data not presented). All data for sterile anther volume $\left(\mathrm{mm}^{3}\right)$ were changed into the relative rate $(\%)$ to the mean volume of fertile anthers in each progeny and are pooled in Figure 6. Figure 6 shows the gentle-sloping distribution of male-sterile seedlings with different rates of anther volumes from nearly $0 \%$ to $90 \%$ with three peaks. The highest peak in the number of seedlings was seen at around $20 \%$ relative anther volume, a medium peak at around 50\% relative volume, and a low peak at around $80 \%$ relative volume. The mean volume of undeveloped small sterile anthers in $\mathrm{F} 8, \mathrm{~F} 11, \mathrm{~F} 13$, and $\mathrm{F} 18$ progenies ranged from $14.1 \%$ to $29.9 \%$ of fertile anthers, whereas that of underdeveloped large sterile anthers ranged from 51.6\% to $74.5 \%$ in F8, F11, and F13 progenies (Table 3).

Histological and cytological observations of anthers during microsporogenesis showed two types of degeneration (Fig. 7). In male-fertile seedlings from 'Hanayu' $\times$ 'Kabosu' (F13), 'Yuzu' $\times$ 'Kusaie' (F16), and 'Yuzu' $\times$ 'Kabosu' (F18) crosses, normal pollen mother cells (PMCs), a large number of one-nucleate microspores and mature pollen grains within enlarged microsporangium were seen in $2 \mathrm{~mm}, 5 \mathrm{~mm}$, and $8 \mathrm{~mm}$ flower buds, respectively. In male-sterile seedlings from the same crosses (F13 and F16), PMCs and tapetal cells did not exist or had degenerated in any flower buds of the seedlings producing undeveloped sterile anthers at anthesis, whereas a small number of microspores and imperfectly enlarged microsporangia with tapetal cells were seen in $5 \mathrm{~mm}$ buds of the seedlings with underdeveloped sterile anthers (Fig. 7).

To increase the segregation data of MS, monoembryonic HY16 with large sterile anthers (Fig. 8A) and monoembryonic 'Kiyomi' with small sterile anthers (Fig. 8B) were pollinated with 'Yuzu' and two grapefruit cultivars 'Foster Pink' and 'Marsh'. In a HY16 × 'Yuzu' cross, a backcross with 'Yuzu', seedlings segregated into 38 with fertile anthers and 22 with sterile anthers (F22 in Table 2): male-fertile and male-sterile phenotypes appeared in a $1: 0.579$ ratio. In the 22 male-sterile seedlings, those with small sterile anthers were more frequently observed than those with large sterile anthers, although the mean volume of the styles in each malesterile seedling was not examined. Male-fertile and malesterile phenotypes appeared in a $1: 0.975$ ratio in the cross of HY16 × 'Foster Pink' (F20 in Table 2) and a 1: 0.636 ratio in the cross of HY16 $\times$ 'Marsh' (F21 in Table 2). When both crosses with two grapefruit cultivars were pooled, male-fertile and male-sterile phenotypes appeared in a $1: 0.93$ ratio in the progenies. Male-fertile and male-sterile phenotypes appeared in a 1:0.295 ratio in the progeny of a 'Kiyomi' $\times$ 'Foster Pink' cross (F26 in Table 2). 
Table 3. Bud length, anther length, anther width, anther volume, and filament length in male-fertile and male-sterile zygotic seedlings derived from six crosses between acid citrus cultivars.

\begin{tabular}{|c|c|c|c|c|c|c|c|c|}
\hline \multirow[b]{2}{*}{ Family } & \multirow[b]{2}{*}{ Cross } & \multirow{2}{*}{$\begin{array}{c}\text { Male fertility } \\
\text { of zygotic } \\
\text { seedlings }\end{array}$} & \multirow{2}{*}{$\begin{array}{c}\text { No. of zygotic } \\
\text { seedlings } \\
\text { examined }\end{array}$} & \multirow{2}{*}{$\begin{array}{l}\text { Length of bud } \\
(\mathrm{mm})^{\mathrm{z}}\end{array}$} & \multicolumn{3}{|c|}{ Anther } & \multirow{2}{*}{$\begin{array}{l}\text { Length of } \\
\text { filament } \\
(\mathrm{mm})^{\mathrm{z}}\end{array}$} \\
\hline & & & & & Length $(\mathrm{mm})^{\mathrm{z}}$ & Width $(\mathrm{mm})^{\mathrm{z}}$ & $\begin{array}{c}\text { Volume }\left(\mathrm{mm}^{3}\right)^{2} \\
(\%)\end{array}$ & \\
\hline \multirow[t]{2}{*}{$\mathrm{F} 4$} & Lisbon $\times$ Yuko & Fertile & 20 & $17.5 \pm 0.8$ & $4.2 \pm 0.2$ & $1.3 \pm 0.0$ & 7.1 & $8.7 \pm 0.4$ \\
\hline & & Sterile $(\text { total })^{\mathrm{y}}$ & 11 & $12.7 \pm 0.4^{*}$ & $3.4 \pm 0.2 *$ & $0.9 \pm 0.1^{*}$ & $2.8(38.8)^{*}$ & $7.1 \pm 0.2 *$ \\
\hline \multirow[t]{2}{*}{ F5 } & Lisbon $\times$ Kabosu & Fertile & 21 & $18.5 \pm 0.6$ & $4.6 \pm 0.1$ & $1.4 \pm 0.0$ & 9.0 & $8.4 \pm 0.2$ \\
\hline & & Sterile (total) $)^{\mathrm{y}}$ & 6 & $12.6 \pm 0.5^{*}$ & $2.9 \pm 0.4^{*}$ & $1.1 \pm 0.1^{*}$ & $3.5(38.9)^{*}$ & $8.1 \pm 0.3$ \\
\hline \multirow[t]{4}{*}{ F8 } & Hanayu $\times$ Lisbon & Fertile & 15 & $15.7 \pm 0.7$ & $4.7 \pm 0.1$ & $1.4 \pm 0.0$ & 9.2 & $8.3 \pm 0.7$ \\
\hline & & Sterile $(L)^{x}$ & 7 & $13.8 \pm 0.6^{*}$ & $4.0 \pm 0.2^{*}$ & $1.3 \pm 0.1^{\mathrm{NS}}$ & $6.8(73.9)^{*}$ & $7.8 \pm 0.3^{\mathrm{NS}}$ \\
\hline & & Sterile $(\mathrm{S})^{\mathrm{w}}$ & 11 & $13.2 \pm 0.6^{*}$ & $2.9 \pm 0.2^{*}$ & $0.8 \pm 0.1^{*}$ & $1.9(20.7)^{*}$ & $7.4 \pm 0.3^{\mathrm{NS}}$ \\
\hline & & Sterile (total) & 18 & $13.5 \pm 0.6^{*}$ & $3.3 \pm 0.2 *$ & $1.0 \pm 0.1 *$ & $3.3(35.9)^{*}$ & $7.6 \pm 0.3^{\mathrm{NS}}$ \\
\hline \multirow[t]{4}{*}{ F11 } & Hanayu $\times$ Yuzu & Fertile & 37 & $12.5 \pm 0.3$ & $3.0 \pm 0.1$ & $1.4 \pm 0.1$ & 5.9 & $9.1 \pm 0.3$ \\
\hline & & Sterile (L) & 2 & $11.8 \pm 0.3^{\mathrm{NS}}$ & $2.6 \pm 0.1 *$ & $1.3 \pm 0.1^{\mathrm{NS}}$ & $4.4(74.5)^{*}$ & $8.9 \pm 0.3^{\mathrm{NS}}$ \\
\hline & & Sterile (S) & 9 & $11.6 \pm 0.3^{\mathrm{NS}}$ & $2.2 \pm 0.1^{*}$ & $0.9 \pm 0.1 *$ & $1.8(29.9)^{*}$ & $8.9 \pm 0.3^{\mathrm{NS}}$ \\
\hline & & Sterile (total) & 11 & $11.7 \pm 0.3^{\mathrm{NS}}$ & $2.3 \pm 0.1^{*}$ & $1.0 \pm 0.1^{*}$ & $2.3(39.0)^{*}$ & $8.9 \pm 0.3^{\mathrm{NS}}$ \\
\hline \multirow[t]{4}{*}{ F13 } & Hanayu $\times$ Kabosu & Fertile & 18 & $13.1 \pm 0.4$ & $3.6 \pm 0.2$ & $1.3 \pm 0.1$ & 6.1 & $8.8 \pm 0.3$ \\
\hline & & Sterile (L) & 8 & $10.7 \pm 0.3 *$ & $2.6 \pm 0.1 *$ & $1.1 \pm 0.1^{*}$ & $3.1(51.6)^{*}$ & $8.6 \pm 0.4^{\mathrm{NS}}$ \\
\hline & & Sterile (S) & 10 & $10.3 \pm 0.3^{*}$ & $2.4 \pm 0.1^{*}$ & $0.7 \pm 0.1^{*}$ & $1.2(19.3)^{*}$ & $8.2 \pm 0.4^{\mathrm{NS}}$ \\
\hline & & Sterile (total) & 18 & $10.5 \pm 0.3^{*}$ & $2.5 \pm 0.1 *$ & $0.9 \pm 0.1^{*}$ & $2.0(32.8)^{*}$ & $8.4 \pm 0.4^{\mathrm{NS}}$ \\
\hline \multirow[t]{2}{*}{ F18 } & Yuzu $\times$ Kabosu & Fertile & 15 & $11.6 \pm 0.3$ & $3.3 \pm 0.1$ & $1.6 \pm 0.1$ & 8.5 & $7.7 \pm 0.3$ \\
\hline & & Sterile $(\mathrm{S})^{\mathrm{v}}$ & 6 & $10.4 \pm 0.2^{*}$ & $1.9 \pm 0.1^{*}$ & $0.8 \pm 0.1^{*}$ & $1.2(14.1)^{*}$ & $5.6 \pm 0.2 *$ \\
\hline
\end{tabular}

${ }^{z}$ Mean \pm SE $(n=$ no. of zygotic seedlings examined). $*$ A single asterisk indicates where male-sterile stamens are significantly different from male-fertile stamens by $t$-test $(P=0.05)$, while ${ }^{\mathrm{NS}}$ "NS" indicates where they are not significantly different.

y Total seedlings with underdeveloped and undeveloped anthers; however, the morphological data in the two groups of the seedlings were not scored in these progenies.

${ }^{x}$ L: Seedlings with large or underdeveloped anthers.

${ }^{w} \mathrm{~S}$ : Seedlings with small or undeveloped anthers.

v Seedlings with undeveloped anthers appeared in this progeny, but those with underdeveloped anthers did not.

\section{Discussion}

The Cytoplasmic types based on mitochondrial DNA fragment polymorphisms in Citrus have been reported (Abkenar et al., 2008; Yamamoto et al., 1993). According to these reports, Citrus cultivars used in this study are classified into four cytoplasm types, i.e., lemon cytoplasm (L-cytoplasm), 'Yuzu' cytoplasm (Y-cytoplasm), pummelo cytoplasm (P-cytoplasm), and satsuma mandarin cytoplasm (M-cytoplasm) (Table 2). Yamamoto et al. (1993) described that 'Villafranca' lemon and 'Kaiseito' sour orange have the same fragment patterns that are slightly different from those of pummelo cultivars, while Abkenar et al. (2008) reported that sour orange cultivars 'Kaiseito' (syn. 'Daidai') and 'Kabusu' have the same fragment pattern as that of pummelo. Gulsen and Roose (2001) reported that sour orange had the same chloroplast DNA fragments found in lemon; they proposed that sour orange is the maternal parent of commercial lemon cultivars including 'Lisbon' and 'Eureka', although they did not study mitochondria DNA. From the results of this report of chloroplast DNA, it may be said that sour orange and lemon cultivars have the same mitochondria DNA because of maternal inheritance of chloroplasts and mitochondria in Citrus. Here, we classified 'Kabusu' sour orange and lemon into
L-cytoplasm. Lemon cultivars used as seed parents generated male-sterile zygotic seedlings, as reported by Frost (1948), but sour orange 'Kabusu' did not, probably because of the small number of zygotic seedlings analyzed (Table 2). Additional study is necessary to clarify whether sour orange cultivars have L-cytoplasm with male-sterile cytoplasmic factors.

Yamamoto et al. (1997) determined on the basis of reciprocal crosses that Iyokan $($ C. iyo) with pummelolike cytoplasm (Yamamoto et al., 1993) has normal cytoplasm; when C. iyo cultivars were used as seed parents, all the progenies derived were male fertile. Regarding male fertility in Citrus, P-cytoplasm is normal, whereas Y-cytoplasm, L-cytoplasm, and Mcytoplasm are sterile (Table 2). It seems that there is no difference in function to induce MS among Y-cytoplasm, L-cytoplasm, and M-cytoplasm, since no obvious morphological differences in male-sterile anthers (undeveloped or underdeveloped anthers) were found among seedlings. When 'Yuzu' was crossed to lemons with L-cytoplasm and to 'Hanayu' with Y-cytoplasm (F1, F3, F8), all crosses generated male-sterile seedlings at different rates. When 'Kabosu' and 'Kizu' were crossed to 'Lisbon' with L-cytoplasm and to 'Yuzu' with Y-cytoplasm (F5, F6, F18, F19), all crosses generated male-sterile seedlings at similar rates. For instance, when 


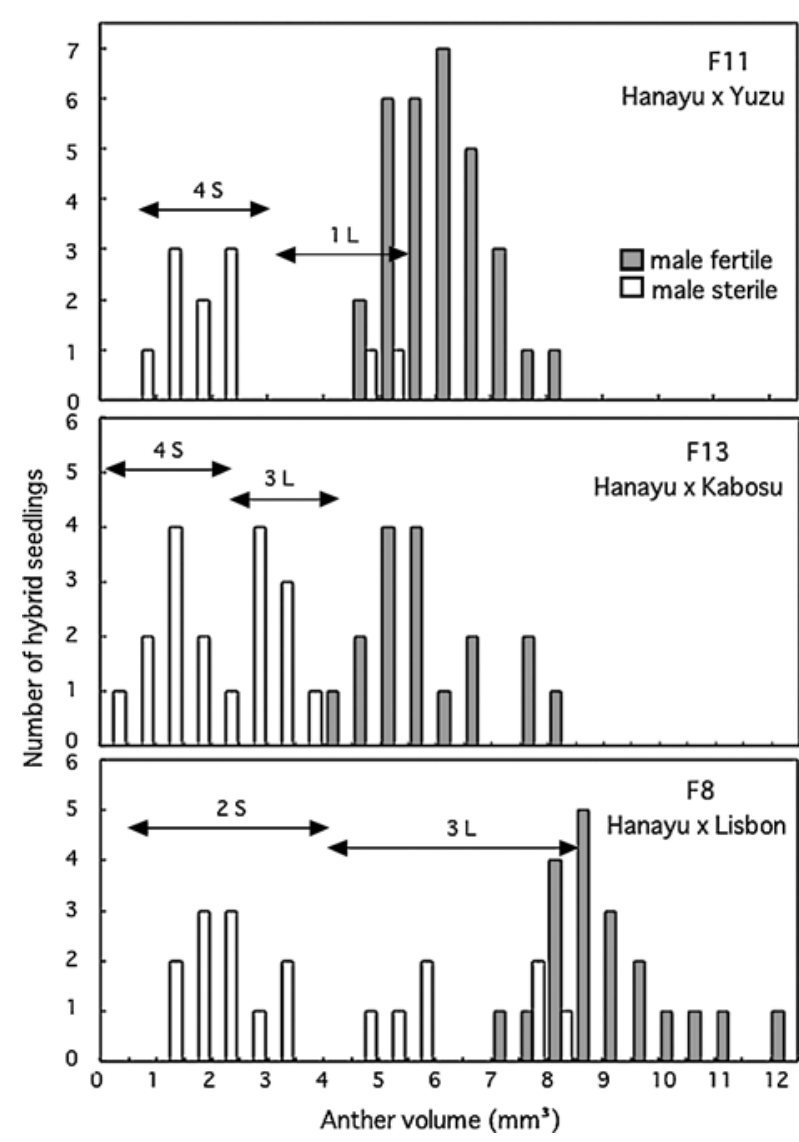

Fig. 5. Distribution frequency of male-sterile zygotic seedlings with undeveloped or underdeveloped anthers with different volumes. Two double-headed horizontal lines indicate the range of seedlings with undeveloped small anthers (S) and that of seedlings with underdeveloped large anthers (L), and numbers attached to $\mathrm{S}$ and $\mathrm{L}$ show the expected segregation ratio of malesterile zygotic seedlings with $\mathrm{S}$ and $\mathrm{L}$ anthers (see Table 2).

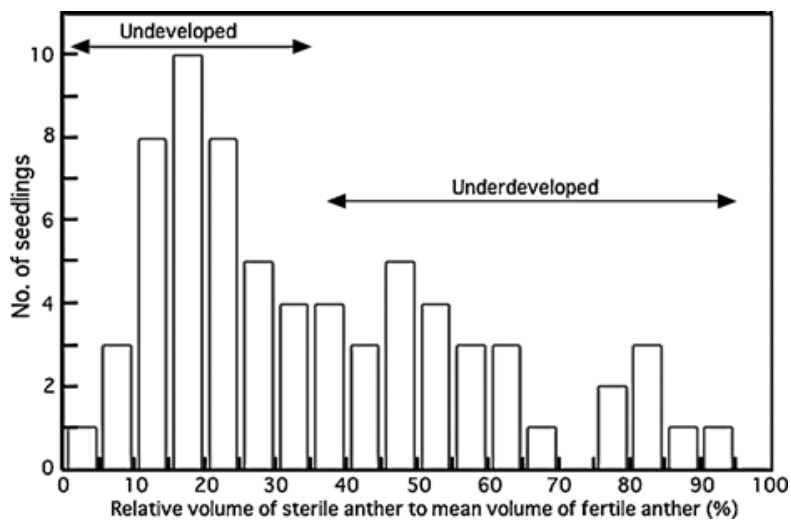

Fig. 6. Distribution frequency of male-sterile zygotic seedlings with undeveloped or underdeveloped anthers with different volumes. Two double-headed horizontal lines indicate the range of anther volume for seedlings with undeveloped small anthers $(\mathrm{S})$ and that with underdeveloped large anthers $(\mathrm{L})$. The border between undeveloped and underdeveloped anther volumes is estimated to be between $30 \%$ and $40 \%$ relative anther volume to the fertile anther volume. Sixty-nine male sterile seedlings from the six crosses listed in Table 3 were used for Figure 6
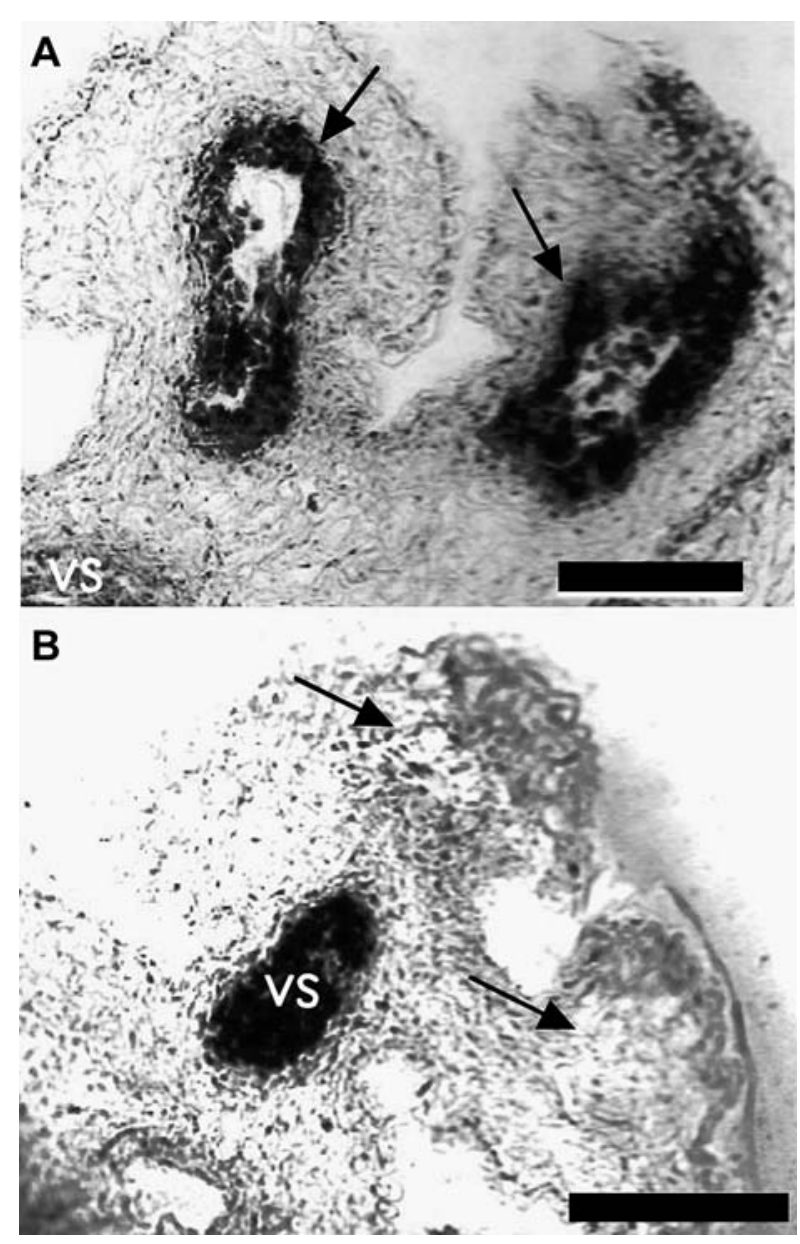

Fig. 7. Cross section of male sterile anthers collected from a $5 \mathrm{~mm}$ flower bud of zygotic seedling HK24 (Hanayu $\times$ Kabosu; F13) with underdeveloped anthers at anthesis (A) and that of zygotic seedling YK61 (Yuzu $\times$ Kabosu; F18) with undeveloped anthers at anthesis (B). Tapetal cells surrounding microsporangium cavity are seen in A (arrows), but none of them are seen in B (arrows). A few microspores were seen in the microsporangia but degenerating in the cavity (A). VS: vascular strand. Bars = $100 \mu \mathrm{m}$.
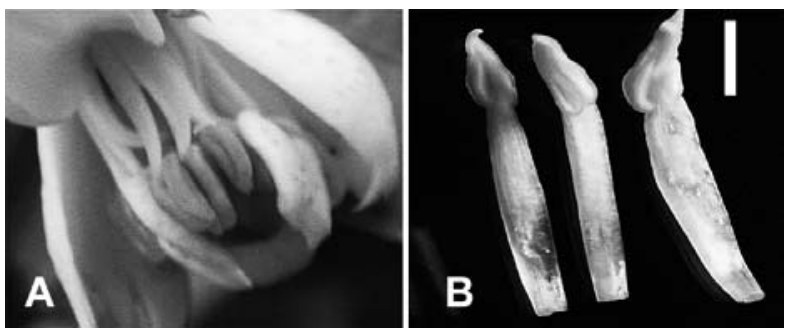

Fig. 8. A flower of HY16 (C. hanaju $\times$ C.junos; F11) with large or underdeveloped sterile anthers (A) and small or undeveloped anthers of 'Kiyomi' tangor (B). Bar $=2 \mathrm{~mm}$.

'Kabosu' was crossed to 'Lisbon' and 'Yuzu', the MF : MS ratio was $21: 11$ and $15: 6$, respectively. When 'Kizu' was crossed to 'Lisbon' and 'Yuzu', the MF : MS ratio was $6: 4$ and $6: 4$, respectively. Based on the chi-square test, the segregation ratios of all these four crosses were $11: 5$. These results also suggest that in both types of 
sterile cytoplasm, segregation of male-sterile genotypes can be explained by the same hypothesis.

The results of this study show that (1) male-fertile and male-sterile zygotic seedlings appeared in various ratios in 21 different crosses between male-fertile acid citrus cultivars, (2) male-sterile zygotic seedlings with large or small sterile anthers appeared in most of the crosses, (3) breakdown of microsporogenesis was due to archesporial degeneration or early PMC degeneration in seedlings with small undeveloped anthers and degeneration of PMCs or microspores in those with large anthers. (4) Segregation of male-fertile (MF) and malesterile (MS) zygotic seedlings in the progeny from the cross of HY16 × 'Yuzu' (F22), a backcross with 'Yuzu', did not fit the $1 \mathrm{MF}$ : $1 \mathrm{MS}$ expected ratio, but fit a $5 \mathrm{MF}$ : $3 \mathrm{MS}$ ratio. This suggests that MS in acid citrus is governed by a serial gene system composed of more than two genes. From the segregation of male-sterile seedlings in the progenies of F20, F21, F22, and F26 (Table 2), the serial gene system for MS in Citrus is inferred as follows: three dominant nuclear fertilityrestorer genes govern male fertility in Citrus plants without normal cytoplasm $(\mathrm{N})$, which shows epistacy over the nuclear genes during microsporogenesis. The three fertility-restorer genes governing male fertility consist of two complementary genes $\left(R_{2}\right.$ and $\left.R_{3}\right)$ and one epistatic $R_{1}$ gene dominating $R_{2}$ and $R_{3}$ genes (Fig. 9). The complementary gene $R_{3}$ is located downstream from $R_{2}$. The recessive homozygosity for $r_{1}$ and $r_{2}$ gene alleles results in small sterile anthers, while that for $r_{1}$ and $r_{3}$ gene alleles results in large sterile anthers with the complement of dominant $R_{2}$ gene allele (Fig. 9). 'Hanayu', 'Yuzu', lemon cultivars, HY16, and 'Kiyomi' have sterile cytoplasm for male fertility. According to this cytoplasmic-genetic system, the genotype of male-sterile HY16 is inferred to be either (S) $r_{1} r_{1} R_{2} r_{2} r_{3} r_{3}$ or (S) $r_{1} r_{1} R_{2} R_{2} r_{3} r_{3}$ from its underdeveloped anther phenotype. The segregation ratio of $1: 0.579$ (or $5 \mathrm{MF}: 3 \mathrm{MS}$ ) in progeny from the cross of HY16 $\times$ 'Yuzu' (F22) indicates that the genotype of HY16 is (S) $r_{1} r_{1} R_{2} r_{2} r_{3} r_{3}$ and 'Yuzu' is (S) $R_{1} r_{1} r_{2} r_{2} R_{3} r_{3}$. The segregation ratio of $1: 0.975$ (or $1 \mathrm{MF}: 1 \mathrm{MS}$ ) in the progeny of the HY16 × 'Foster Pink' cross (F20) and the segregation ratio of $1: 0.295$ (or $3 \mathrm{MF}: 1 \mathrm{MS}$ ) in the progeny of the 'Kiyomi' $\times$ 'Foster Pink' cross (F26) indicate that the genotype of 'Kiyomi' with aborted or small anthers is (S) $r_{1} r_{1} r_{2} r_{2} R_{3} r_{3}$, whereas that of grapefruit with pummelo cytoplasm (Yamamoto et al., 1993; described later) is either $(\mathrm{N}) r_{1} r_{1} R_{2} R_{2} R_{3} r_{3}$ or (N) $R_{1} r_{1} R_{2} R_{2} r_{3} r_{3}$.

Based on the segregation ratios in the progenies of 'Yuzu' $\left(R_{1} r_{1} r_{2} r_{2} R_{3} r_{3}\right)$ in F1, F3, F11, F14, F15, F16, F17, F18, and F19, MS genotypes revealed by fertilityrestorer genes were estimated in two lemon cultivars $\left(R_{1} r_{1} R_{2} r_{2} r_{3} r_{3}\right)$, 'Chinotto' $\left(R_{1} R_{1} R_{2} r_{2} R_{3} r_{3}\right)$, 'Kabusu' sour orange $\left(R_{1} R_{1} R_{2} r_{2} R_{3} r_{3}\right)$, 'Sudachi' $\left(R_{1} r_{1} R_{2} r_{2} r_{3} r_{3}\right)$, 'Hanayu' $\left(r_{1} r_{1} R_{2} r_{2} R_{3} r_{3}\right)$, 'Kabosu' $\left(r_{1} r_{1} R_{2} r_{2} R_{3} r_{3}\right)$,

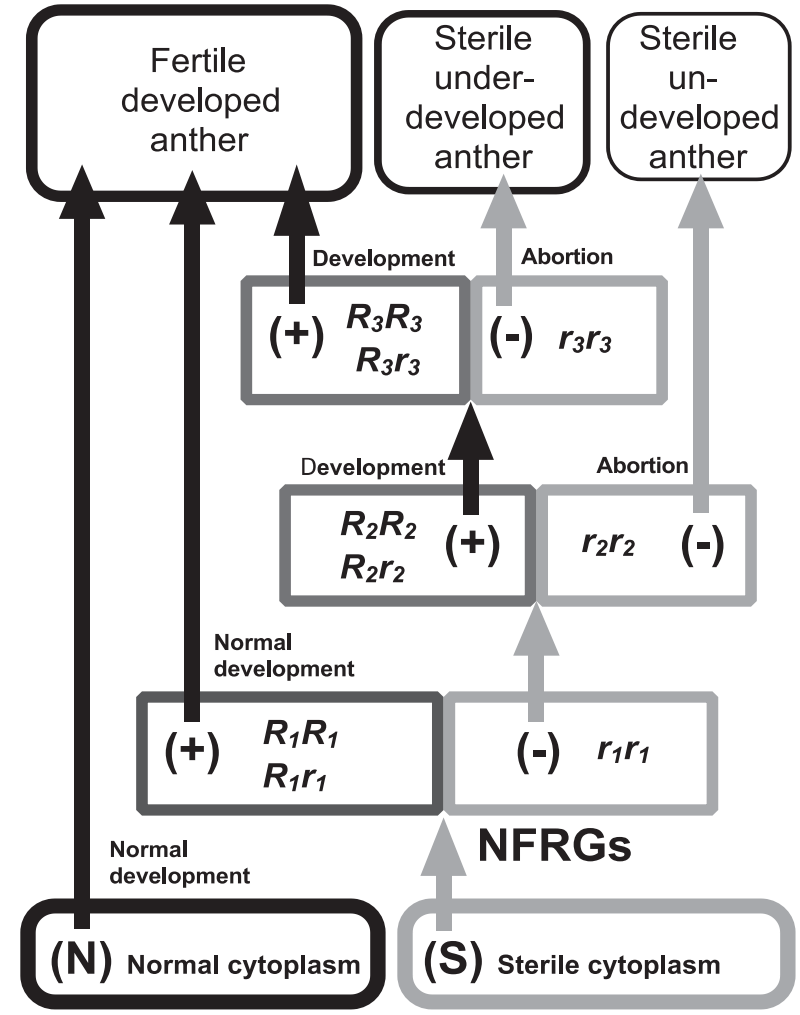

Fig. 9. Mechanism for appearance of cytoplasmic-genetic male sterility in acid citrus. Symbols in parentheses represent presence $(+)$ or absence $(-)$ of fertility restoration by dominant nuclear fertility-restorer genes (NFRGs). Letters in rectangular circles show genotype(s) in each of three NFRGs. Gene alleles $R_{1}, R_{2}$, and $R_{3}$ are dominant to gene alleles $r_{1}, r_{2}$, and $r_{3}$, respectively. Gene $r_{1}$ is epistatic to genes $r_{2}$ and $r_{3}$ that are complementary with downstream location of the $r_{3}$ gene. Letters in parentheses in the round circles show cytoplasmic factors. Arrows indicate the development of stamen morphogenesis and microsporogenesis.

'Kizu' $\left(r_{1} r_{1} R_{2} r_{2} R_{3} r_{3}\right)$, and 'Kusaie' lime $\left(r_{1} r_{1} R_{2} r_{2} R_{3} r_{3}\right)$. The MS genotype of 'Yuko' $\left(r_{1} r_{1} R_{2} r_{2} R_{3} r_{3}\right)$ was estimated in the progeny of F4 with 'Lisbon' $\left(R_{1} r_{1} R_{2} r_{2} r_{3} r_{3}\right)$ as a seed parent. Goodness-of-fit tests of the expected segregation ratio significantly supported these estimated genotypes (Tables 2 and 4). The MS genotypes of 'Bouquet de Fleurs' and 'Etrog' citron, which generated male-sterile zygotic seedlings in F9 and F14 (Table 2), are considered to be heterozygous for one, two or all three nuclear genes, but this could not be assessed because of the small number of seedlings examined.

The goodness-of-fit test for segregation in progenies of F12, F23, F24, and F25 with 'Sudachi' as a pollen or seed parent suggests that 'Sudachi' has normal cytoplasm (N) resulting in male fertility (Table 2 ). Hence, the MS genotype of 'Sudachi' was estimated to be (N) $R_{1} r_{1} R_{2} r_{2} r_{3} r_{3}$. It was not assessed whether 'Kabusu' sour orange has sterile cytoplasm, because in the progeny of F7 with 'Kabusu' sour orange as a seed parent, malesterile seedlings were not generated, although male- 
Table 4. Segregation of male sterile zygotic seedlings with large (underdeveloped) anthers and those with small (undeveloped) anthers in the progenies of four crosses with four acid citrus cultivars.

\begin{tabular}{|c|c|c|c|c|c|c|c|}
\hline \multirow{2}{*}{ Family } & \multirow{2}{*}{ Cross } & \multicolumn{3}{|c|}{ Observed ratio } & \multirow{2}{*}{$\begin{array}{c}\text { Expected ratio } \\
\text { Fertile }: \text { Large }: \text { Small }\end{array}$} & \multirow{2}{*}{$\chi^{2}$} & \multirow{2}{*}{$P$} \\
\hline & & Fertile & Large & Small & & & \\
\hline F8 & Hanayu $\times$ Lisbon & 46 & 7 & 11 & $11: 3: 2$ & 3.2999 & 0.192 \\
\hline F11 & Hanayu $\times$ Yuzu & 37 & 2 & 9 & $11: 1: 4$ & 1.5682 & 0.457 \\
\hline $\mathrm{F} 13^{\mathrm{z}}$ & Hanayu $\times$ Kabosu & 31 & 9 & 10 & $9: 3: 4$ & 0.8089 & 0.667 \\
\hline $\mathrm{F} 13^{\mathrm{y}}$ & Hanayu $\times$ Kabosu & 31 & 8 & 11 & $9: 3: 4$ & 0.6756 & 0.713 \\
\hline F18 & Yuzu $\times$ Kabosu & 15 & 0 & 6 & $11: 1: 4$ & 1.4416 & 0.486 \\
\hline
\end{tabular}

${ }^{z}$ Based on the postulation that one male-sterile zygotic seedling, whose anther size was not measured, generated small sterile anthers (see Table 2).

y Based on the postulation that the one male-sterile zygotic seedling, whose anther size was not measured, generated large sterile anthers (see Table 2).

sterile seedlings were generated in F17 with 'Kabusu' sour orange as a pollen parent; a large number of zygotic seedlings are necessary to determine cytoplasmic sterility. Hence, the MS genotype of 'Kabusu' was estimated as ( $\mathrm{S}$ ?) $R_{1} r_{1} R_{2} r_{2} R_{3} R_{3}$ (Table 2).

In general, MS in higher plants is categorized into three types, i.e., genetic, cytoplasmic, and cytoplasmicgenetic (Allard, 1960). Except for some male-sterile Citrus cultivars suspected to be genetic (Hu et al., 2007; Iwamasa, 1966), MS in Citrus is cytoplasmic-genetic (Kaul, 1988), and is sporogenous based on the expression of MS genes, which act in premeiotic and/or postmeiotic stages of microsporogenesis and hamper the normal development of sporogenous tissues (Iwamasa, 1966), tapetal cells (Iwamasa, 1966; Nakamura, 1943; Osawa. 1912), and, subsequently, PMCs (Frost, 1948; Osawa, 1912) and microspores (Nakamura, 1943; Osawa, 1912). All types of these hindrances to development were observed in male-sterile zygotic seedlings obtained in this study. Iwamasa (1966) reported that in satsuma mandarin hybrids, the filaments of sterile stamens were somewhat shorter than those of normal fertile plants. In the present study, the filaments of sterile stamens were also shorter than those of normal fertile plants in most crosses, and significantly shorter and thinner in six malesterile zygotic seedlings from the cross of 'Yuzu' $\times$ 'Kabosu' (Table 3). The six sterile zygotic seedlings examined had undeveloped anthers. Thus, the significantly shorter filaments in male-sterile zygotic seedlings were associated with their undeveloped small anthers whose mean volume was about $20 \%$ that of normal anthers of fertile zygotic seedlings (Fig. 6). It is clear that the male-sterile cytoplasmic factors in 'Yuzu' and 'Lisbon' lemon as well as those in satsuma mandarin affect stamen morphogenesis from the early stage of development in the absence of nuclear restoration factors.

The estimated male-sterile genotypes of 23 cultivars indicate that 16 of the 26 crosses generated male-sterile seedlings with underdeveloped large (MSL) and undeveloped small (MSS) anthers with the expected ratios of $1: 2,1: 4,3: 1,3: 2$, or $3: 4$, and that three (F2, F10, F17) and three (F20, F21, F26) of the 26 crosses generated male-sterile seedlings with only undeveloped (small) and only underdeveloped (large) sterile anthers, respectively (Table 2). The frequency distributions of male-sterile zygotic seedlings with different anther volumes in three (Fig. 5) and pooled progenies (Fig. 6) almost agreed with the expected segregation ratios of the progenies. Furthermore, the chi-square test supported that MF, MSL, and MSS seedlings segregate in ratios of $11: 3: 2$ for F8, 11:1:4 for F11, 9:3:4 for F13, and $11: 1: 4$ for F18 (Table 4). Yamamoto et al. (1992b, 1997) and Nakano et al. (2001) have reported that 'Kiyomi' tangor with satsuma mandarin cytoplasm uniquely generated male-sterile seedlings with aborted or undeveloped anthers in crosses with several Citrus cultivars as pollen parents, and they proposed two and three homomeric nuclear genes controlling undeveloped anther formation, respectively. The present findings that the crosses of 'Kiyomi' $\times$ 'Foster Pink' and HY16 $\times$ 'Foster Pink' generated male-sterile seedlings with underdeveloped anthers but did not generate those with aborted or undeveloped anthers indicate the existence of three dominant nuclear fertility-restorer genes, a different fertility-restorer gene system from their proposal.

In higher herbaceous crops with cytoplasmic-genetic type of MS, genetic control of fertility restoration is conditioned by one or more dominant fertility-restorer genes, which are especially influenced by temperature and photoperiod and interact with many other major or minor genes (Kaul, 1988). Considering the function of the three dominant nuclear fertility-restorer genes in Citrus, the epistatic nuclear-restorer gene $R_{1}$ induces total restoration of fertility, whereas the complementary gene $R_{2}$ located upstream from $R_{3}$ restores early morphogenesis of the stamen and archesporial cell development but may not perfectly restore tapetum cell development. The complementary gene $R_{3}$ located downstream is considered to restore tapetum cell development and subsequent microsporogenesis and pollen formation. Iwamasa (1966) has described that the morphology of sterile anthers may be more or less modified by various environmental factors such as temperature, although it is mainly controlled by genetic factors. By our observation of MS in zygotic seedlings under natural or greenhouse conditions for more than ten years, it may be said that fertility-restorer gene 
expressions are not obviously influenced by temperature and photoperiod, since male-sterile zygotic seedlings did not show any pollen formation or pollen fertility.

Cybrids with satsuma mandarin cytoplasm were produced or planned to improve male-fertile seeded Citrus cultivars to male-sterile seedless cultivars (Cai et al., 2007; Guo et al., 2004); however, there have been no reports about the MS of these cybrids. The present study indicates that determination of genotypes for nuclear-fertility-restorer genes of the target fertile cultivars is important for cybrid operation. As suggested in Figure 9, recessive homozygous genotype for the epistatic gene $\left(r_{1} r_{1}\right)$ is essential for MS of the target cultivars. In addition to this, it is necessary that either complementary gene $r_{2}$ or $r_{3}$ is recessive homozygous.

In many species, such as Petunia hybrida (Bino, 1985) and Zea mays (Lee et al., 1979), as well as Citrus species forming underdeveloped anthers, abnormality in the tapetal cells is the first sign of aberrant development. In some types such as cytoplasmic male-sterile (CMS) group $\mathrm{S}$ in Zea mays, abnormalities occur only in the microspores in the very late stage of pollen development irrespective of tapetal cell development (Lee et al., 1980). The distribution frequency of seedlings with different volumes of sterile anthers showed three peaks (Fig. 6); the third peak consisting of seven MS seedlings with more than $75 \%$ of fertile anther volume is considered to be underdeveloped anthers in this study. At present, however, it is not clear whether the fourth nuclear fertility-restorer gene controls this third group.

The cytoplasmic factors resulting in cytoplasmicgenetic male sterility (CGMS) in Citrus are not known at present, but it is generally known that differential expression of mitochondrial genes during pollen development may account for pollen abortion in CMS plants (William and Levings, 1992). Hu et al. (2006) reported the differential expression of mitochondrial genes during microsporogenesis in male-sterile satsuma mandarin.

In either case, whether it is undeveloped or underdeveloped, resulting in complete male sterility, will be of great value in the future breeding of acid citrus fruits as has been reported for other citrus fruits (Iwamasa, 1966; Nakano et al., 2001; Vardi et al., 2008). Eleven male-fertile Citrus cultivars, whose genotypes have been identified (Table 2), show either recessive homozygosity or heterozygosity for the epistatic gene $R_{l}\left(6 r_{l} r_{l}: 5 R_{l} r_{l}: 0 R_{1} R_{l}\right)$ and high heterozygosity for complementary genes $R_{2}\left(1 r_{2} r_{2}: 10 R_{2} r_{2}: 0 R_{2} R_{2}\right)$ and $R_{3}$ $\left(2 r_{3} r_{3}: 7 R_{3} r_{3}: 2 R_{3} R_{3}\right)$. The high frequency of recessive homozygosity and/or heterozygosity of the epistatic gene and complementary genes in these cultivars with different origins suggest that Citrus species and cultivars developed from several elementary species through complex hybridization processes (Barrett and Rhodes, 1976; Li et al., 2010; Scora, 1975) are highly heterozygous for the three nuclear fertility-restorer genes; this high heterozygosity in Citrus undoubtedly provides the potential to breed various male-sterile or seedless Citrus cultivars in combination with sterile M-, L-, or Y-cytoplasm.

\section{Literature Cited}

Abkenar, A. A., S. Isshiki, R. Matsumoto and Y. Tashiro. 2008. Comparative analysis of organelle DNA in acid citrus grown in Japan using PCR-RFLP method. Genet. Res. Crop. Evol. 55: 487-492.

Aleza, P., J. Juarez, J. Cuenca, P. Ollitrault and L. Navarro. 2010. Recovery of citrus triploid hybrids by embryo rescue and flow cytometry from $2 \mathrm{x} \times 2 \mathrm{x}$ sexual hybridization and its application to extensive breeding programs. Plant Cell Rep. 29: 1023-1034.

Allard, R. W. 1960. Principles of plant breeding. John Wiley \& Sons, New York.

Barrett, C. H. and A. M. Rhodes. 1976. A numerical taxonomic study of affinity relationships in cultivated citrus and its close relatives. Syst. Botany 1: 105-136.

Bino, R. J. 1985. Histological aspects of microsporogenesis in fertile, cytoplasmic male sterile and restored fertile Petunia hybrida. Theor. Appl. Genet. 69: 423-428.

Cai, X. D., J. Fu, X. X. Deng and W. W. Guo. 2007. Production and molecular characterization of potential seedless cybrid plants between pollen sterile Satsuma mandarin and two seedy Citrus cultivars. Plant Cell, Tiss. Org. Cult. 90: 275-283.

Frost, H. B. 1948. Seed reproduction: development of gametes and embryos. p. 767-816. In: H. J. Webber and L. D. Batchelor (eds.). The Citrus Industry, Vol. 1. University of California Press, Berkeley.

Furr, J. R., W. C. Cooper and P. C. Reece. 1947. An investigation of flower formation in adult and juvenile citrus trees. Amer. J. Bot. 34: 1-8.

Grosser, J. W., G. A. Moore and J. F. G. Gmitter. 1989. Interspecific somatic hybrid plants from the fusion of "Key" lime (Citrus aurantifolia) with "Valencia" sweet orange (Citrus sinensis) protoplasts. Sci. Hortic. 39: 23-29.

Gulsen, O. and M. L. Roose. 2001. Chloroplast and nuclear genome analysis of the parentage of lemons. J. Amer. Soc. Hort. Sci. 126: 210-215.

Guo, W. W., Y. J. Cheng and X. X. Deng. 2002. Regeneration and molecular characterization of intergeneric somatic hybrids between Citrus reticulata and Poncirus trifoliata. Plant Cell Rep. 20: 829-834.

Guo, W. W., D. Prasad, Y. J. Cheng, P. Serrano, X. X. Deng and J. W. Grosser. 2004. Targeted cybridization in citrus: transfer of Satsuma cytoplasm to seedy cultivars for potential seedlessness. Plant Cell Rep. 22: 752-758.

Hu, Z. Y., Z. Tong, J. Wei, H. L. Yi and X. X. Deng. 2006. Mitochondrial gene expression in stamens is differentially regulated during male gametogenesis in Citrus unshiu. J. Hortic. Sci. Biotech. 81: 565-569.

Hu, Z. Y., M. Zhang, O. Wen, J. Wei, H. Yi and X. Deng. 2007. Abnormal microspore development leads to pollen abortion in a seedless mutant of 'Ougan' mandarin (Citrus suavissima hort. ex Tanaka). J. Amer. Soc. Hort. Sci. 132: 777-782.

Iwamasa, M. 1966. Studies on the sterility in the genus Citrus with special reference to seedlessness. Bull. Hort. Res. Sta. (Minist. of Agric. \& Forest.), Japan B6: 1-76.

Iwamasa, M. and Y. Oba. 1973. Precocious flowering of citrus seedlings. Proc. First Intl. Citrus Symp. 2: 205-213.

Kaul, M. L. H. 1988. Male sterility in higher plants. SpringerVerlag, Berlin. 
Kim, J. H., A. Wakana, T. Sekiya, Y. Tanimoto, B. X. Ngo and K. Sakai. 2010. Precocious flowering of Citrus seedlings and short juvenility of Poncirus seedlings: usage for genetic analysis and breeding. p. 327-334. In: X. Deng, J. Xu, S. Lin and R. Guan (eds.). Proc. Intl. Soc. Citriculture, Vol. 1. China Agriculture Press, Beijing.

Lee, S. L. G., V. E. Gracen and E. D. Earle. 1979. The cytology of pollen abortion in C-cytoplasmic male-sterile corn anthers. Amer. J. Bot. 66: 141-148.

Lee, S. L. G., V. E. Gracen and E. D. Earle. 1980. The cytology of pollen abortion in S-cytoplasmic male-sterile corn anthers. Amer. J. Bot. 67: 237-245.

Li, D., W. Shi and X. Deng. 2002. Agrobacterium-mediated transformation of embryogenic calluses of Ponkan mandarin and the regeneration of plants containing the chimeric ribonuclease gene. Plant Cell Rep. 21: 153-156.

Li, X., R. Xie, Z. Lu and Z. Zhou. 2010. The origin of cultivated citrus as inferred from internal transcribed spacer and chloroplast DNA sequence and amplified fragment length polymorphism fingerprints. J. Amer. Soc. Hort. Sci. 135: 341-350.

Nakamura, M. 1943. Cytological and ecological studies on the genus Citrus, with special reference to the occurrence of sterile pollen grain. Memoirs Fac. Sci. Agr., Taihoku Imp. Univ. 27: 53-159.

Nakano, M., H. Nesumi, T. Yoshioka and T. Yoshida. 2001. Segregation of plants with undeveloped anthers among hybrids derived from the seed parent, 'Kiyomi' (Citrus unshiu $\times$ C. sinensis). J. Japan. Soc. Hort. Sci. 70: 539-545.

Nishiura, M., T. Shichijo, I. Ueno, M. Iwamasa, T. Kihara, Y. Yamada, T. Yoshida and T. Iwasaki. 1983. New citrus cultivar 'Kiyomi' tangor. Bull. Fruit Tree Res. Sta. B10: 1-9 (In Japanese with English abstract).

Ngo, B. X., J-H. Kim, A. Wakana, S. Isshiki and T. Mori. 2011. Estimation of self-incompatibility genotypes of Citrus cultivars with Got-3 allozyme markers. J. Japan. Soc. Hort. Sci. 80: 284-294.

Okudai, N., R. Matsumoto, I. Oiyama, T. Takahara, D. Ishiuchi, K. Asada and M. Yamamoto. 1991. New citrus cultivar 'Seihou'. Bull. Fruit Tree Res. Sta. 21: 43-49 (In Japanese with English Summary).

Oppenheim, J. D. and O. H. Frankel. 1929. Investigations into the fertilization of the Jaffa orange I. Genetica 11: 369-374.

Osawa, I. 1912. Cytological and experimental studies in Citrus. J. Coll. Agr. Tokyo Imp. Univ. 4: 83-116.

Rahman, M. M., N. Nito and S. Isshiki. 2001. Cultivar identification of 'Yuzu' (Citrus junos Sieb. ex Tanaka) and related acid citrus by leaf isozymes. Sci. Hortic. 87: 191-198.

Raza, H., M. M. Khan and A. A. Khan. 2003. Seedless in Citrus. Intl. J. Agr. Biol. 5: 388-391.

Scora, R. W. 1975. On the history and origin of Citrus. Bull. Torrey Bot. Club 102: 369-375.

Shivanna, K. R. and V. K. Sawhney. 1997. Pollen biology and pollen biotechnology: an introduction. p. 1-13. In: K. R. Shivanna and V. K. Sawhney (eds.). Pollen biotechnology for crop production and improvement. Cambridge University Press, London.

Soost, R. K. and J. W. Cameron. 1980. 'Oroblanco' a triploid pummelo-grapefruit hybrid. HortScience 15: 667-669.

Soost, R. K. and J. W. Cameron. 1985. 'Melogold' a triploid pummelo-grapefruit hybrid. HortScience 20: 1134-1135.

Sykes, S. R. and S. Lewis. 1996. Comparing Imperial mandarin and Silver Hill satsuma mandarin as seed parents in a breeding program aimed at developing new seedless Citrus cultivars for Australia. Aust. J. Exp. Agr. 36: 731-738.

Vardi, A., I. Levin and N. Carmi. 2008. Induction of seedlessness in Citrus: from classical techniques to emerging biotechnological approaches. J. Amer. Soc. Hort. Sci. 133: 117-126.

Wakana, A., Y. Fujiwara, K. Sakai, I. Fukudome and K. Yasukochi. 2005. Frequent occurrence of precocious flowering in zygotic seedlings derived from crosses with a monoembryonic and male sterile acid citrus hybrid between Yuzu (C. junos Sieb. ex Tanaka) and Hanayu (C. hanaju hort. ex Shirai). J. Fac. Agr. Kyushu Univ. 50: 615-624.

William, M. E. and C. S. Levings. 1992. Molecular biology of cytoplasmic male sterility. Plant Breeding Review 10: 23-51.

Wu, J., A. R. Ferguson and P. A. Mooney. 2005. Allotetraploid hybrids produced by protoplast fusion for seedless triploid Citrus breeding. Euphytica 141: 229-235.

Yamada, Y., Y. Ito, I. Ueno and T. Yoshida. 1991. Precocious flowering in citrus and kumquat seedlings. Bull. Fruit Tree Res. Sta. 20: 13-23 (In Japanese with English summary).

Yamamoto, M., N. Okudai and R. Matsumoto. 1992a. Segregation for aborted anthers in hybrid seedlings using Citrus nobilis $\times$ C. deliciosa cv. Encore as the seed parent. J. Japan. Soc. Hort. Sci. 60: 785-789 (In Japanese with English summary).

Yamamoto, M., N. Okudai and R. Matsumoto. 1992b. Study on the inheritance of aborted anthers in citrus using seed parents having aborted anthers. J. Japan. Soc. Hort. Sci. 60: 791-797 (In Japanese with English summary).

Yamamoto, M., S. Kobayashi, Y. Nakamura and Y. Yamada. 1993. Phylogenic relationships of citrus revealed by RFLP analysis of mitochondrial and chloroplast DNA. Japan. J. Breeding 43: 355-365.

Yamamoto, M., R. Matsumoto, N. Okudai and Y. Yamada. 1997. Aborted anther of Citrus result from gene-cytoplasmic male sterility. Sci. Hortic. 70: 9-14.

Ye, W., Y. Qin, Z. Ye, D. S. J. A. Teixeira, L. Zhang, X. Wu, S. Lin and G. Hu. 2009. Seedless mechanism of a new mandarin cultivar 'Wuzishatangju' (Citrus reticulata Blanco). Plant Sci. 177: 19-27.

Yoshida, T., H. Nesumi, T. Yoshioka, Y. Ito, I. Ueno and Y. Yamada. 2005. 'Kankitsu Chukanbohon Nou 5 Gou' ('Citrus Parental Line Norin No. 5') is useful for breeding seedless and early maturing cultivars. Bull. Natl. Inst. Fruit Tree Sci. 4: 47-52 (In Japanese with English summary). 